\title{
ANGIOTENSIN CONVERTING ENZYME INHIBITORS USE AND SPONTANEOUS ABORTION IN MOTHERS WITH SYSTEMIC LUPUS ERYTHEMATOSUS IN A TERTIARY HOSPITAL
}

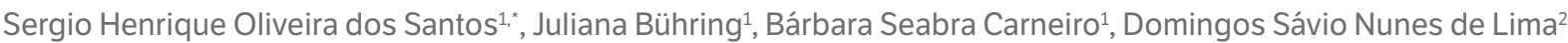

1. Hospital Universitário Getúlio Vargas, Manaus (AM), Brazil. 2.Universidade Federal do Amazonas, Manaus (AM), Brazil.

${ }^{\star}$ Corresponding author: sergio.henrique@live.com

\section{BACKGROUND}

Systemic lupus erythematosus (SLE) is an autoimmune disease that has a variable clinical picture and a remitting-recurrent character. It can reach a female:male ratio 9:1, affecting negatively maternal reproductive aspect. In SLE management, angiotensinconverting enzyme inhibitors (ACEI) are used mainly in lupus nephritis (LN), a hypertension. Exposure in the first trimester of pregnancy may be associated with fetal malformations and adverse events. The aims of the present study were to describe the frequency of ACEl use and spontaneous abortion (SA) in SLE mothers, compare the difference of SA proportions between users and nonusers of ACEI six months before pregnancy, and to verify if there was association between ACEI use six months before pregnancy and SA in the sample.

\section{MATERIALS AND METHODS}

A descriptive cross-sectional study was performed in a rheumatology service of a tertiary hospital that follows about 800 patients. The patients who had at least one pregnancy from January 2003 until December 2019 and were in regular follow-up were included. Patients unable to provide data about the delivery outcome were excluded; categorical variable was correlated using the Fisher's exact test and the proportions were tested using the binomial test.

\section{RESULTS}

One hundred and twenty-two patients were included with 92 pregnancies. Two patients were excluded because lack of data about ACEl use six months before pregnancy. The mean age at pregnancy was 28.4 years, standard deviation (SD) 5.6 years. The mean disease length was 6.4 years, SD 4.5 years. There was ACEl use six months before pregnancy for hypertension or LN in 14 pregnancies $(11.5 \%)$ and seven pregnancies ended in spontaneous abortion (50\%) in this group ( $p<0.001$ ) (Fig. 1). Comparing the groups exposed nonexposed to ACEl, the proportion of spontaneous abortion was higher in the former $(p=0.004)$. There was a positive association between ACEl use six months before pregnancy and spontaneous abortion, $(p=0.004, \mathrm{OR}=6.06,95 \% \mathrm{Cl}=1.86-19.7)$.

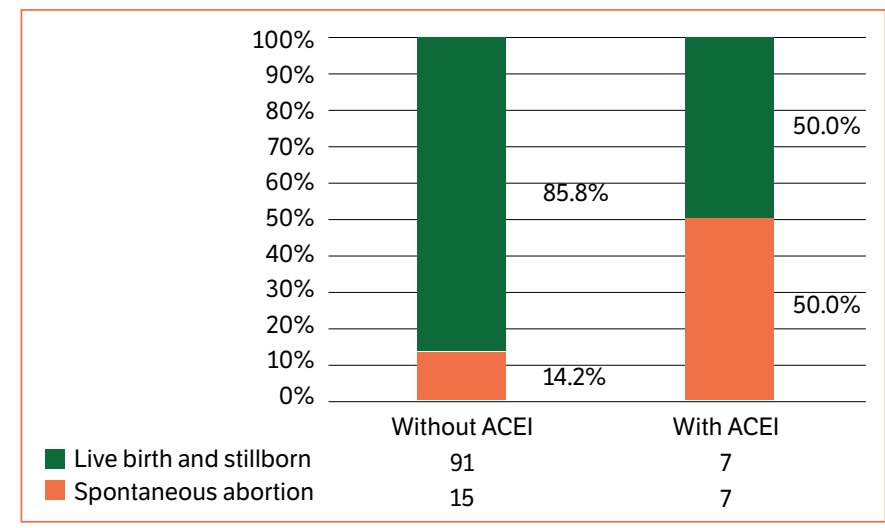

Figure 1. Distribution of frequency of spontaneous abortion by use of ACEl six months before pregnancy. 


\section{CONCLUSION}

In our sample, we could verify that angiotensin-converting enzyme inhibitors use, six months before pregnancy was noted, was a risk factor to spontaneous abortion. Angiotensin-converting enzyme inhibitors are important drugs used in treatment of $L N$ and hypertension, but their danger in pregnancy is well known as well. Since the exact time of conception could not be established in our study, so many patients might have become pregnant in use of ACEI. Studies evaluating preconceptional issues in this population should be conducted in order to identify risk factors other than ACEI to provide better outcomes in patients with SLE. 